\title{
A marcação do plural no sistema Signwriting: uma abordagem morfológica
}

Débora Campos Wanderley ${ }^{1}$

Marianne Rossi Stumpf ${ }^{2}$

\section{Resumo}

Neste artigo, apresentaremos alguns sinais escritos referentes aos aspectos linguísticos da marcação do plural na Língua Brasileira de Sinais (Libras). O objetivo deste trabalho é analisar a flexão de plural nas produções escritas feitas em sala de aula, por alunos surdos e ouvintes, na disciplina de Escrita de Sinais II do curso de Letras Libras da Universidade Federal de Santa Catarina (UFSC), em 2014. Pretende-se também discutir as estratégias envolvidas no ensino-aprendizagem da Língua Brasileira de Sinais, por meio da escrita e pelo sistema SignWriting. Com isso, identificamos que os produtores dos textos analisados na nossa pesquisa usam, na escrita de sinais, a flexão de plural. Nessa marcação, encontramos um caráter de regularidade representado pelos sinais, que poderão auxiliar na teoria dos estudos linguísticos das línguas de sinais.

Palavras-chave: Libras. Plural. SignWriting.

1 Professora de Letras Libras da Universidade Federal de Santa Catarina (UFSC), Florianópolis, Brasil - E-mail: deboraufsclibras@gmail.com

2 Professora da Pós-Graduação em Linguística e Letras Libras da Universidade Federal de Santa Catarina (UFSC), Florianópolis, Brasil - E-mail: stumpfmarianne@gmail.com 


\section{Abstract}

In this paper, we present some signwriting referring to the linguistic aspects of the plural marks in the Brazilian Sign Language. The objective of this study is to analyze the plural inflexion in written productions made in SignWriting II class for deaf and listeners students, from the Letras Libras course at the Federal University of Santa Catarina (UFSC), in 2014. We also intend to discuss how strategies can be developed in the brazilian sign language teaching and learning process through writing, specifically the SignWriting system. Thus, we identify that the producers of the texts analyzed in our study used the plural inflexion in the signwriting. Finally, the analysis of the marks in which we found regularities represented by the signs can contribute to the sign language linguistic theory field of studies.

Keywords: Brazilian sign language. Plural. SignWriting.

\section{Introdução}

A escrita de sinais do SignWriting (SW) é um sistema alfabético de glifos que representa as línguas de sinais naturais, originado a partir de um sistema de notação de dança desenvolvido por Valerie Sutton em 1974 (SUTTON, 1998). Linguistas investigaram características de línguas de sinais naturais e contaram com um grupo de signatários nativos dos EUA, falantes da American Sign Language (ASL). De seus trabalhos sobre o sistema de Sutton, evoluiu-se para um sistema de escrita de sinais utilizado internacionalmente. O SignWriting inclui todos os parâmetros (a configuração de mão, o ponto de articulação ou locação, o movimento, a orientação e as expressões não manuais) identificados por pesquisadores das línguas de sinais. Assim, podem-se registrar oficialmente as línguas de sinais para a escrita de sinais, que antes era uma língua ágrafa ou traduzida para outros idiomas das línguas orais na escrita, e por isso não 
incluía nenhum de seus próprios parâmetros. Atualmente, os glifos do SignWriting são usados para fins de comunicação linguística, educacional, computacional, artística e convencional, representando catorze diferentes línguas de sinais naturais.

No Brasil, de 1996 a 2001, o sistema SignWriting foi adaptado e organizou-se um manual que apontava como escrever os sinais da Libras utilizando-o. Durante e a partir disso, houve a realização de palestras e seminários no intuito de criar softwares de SignWriting para serem empregados no computador. Além disso, aconteceram aulas em algumas escolas de surdos e foi implantada a primeira disciplina no curso de graduação em Letras Libras, em 2007. Desde então, cresceram os cursos e as pesquisas sobre o tema nessa área.

Atualmente, alguns pesquisadores discutem o funcionamento do SignWriting, como Campos e Stumpf (2012). Dentre outros sistemas, o SignWriting é o único que traz uma exploração significativa e nova no espaço gráfico, que é uma parte importante da anotação icônica da forma material dos signos e contempla com riqueza a anotação para os parâmetros não manuais, essencial à estrutura das línguas de sinais.

A leitura de sinais precisa contar também com informações não visuais que envolvem a competência linguística do leitor, seu conhecimento sobre o conteúdo do texto e o conhecimento prévio do modo como as palavras integram-se na linguagem, envolvendo a gramática e o sentido. Assim, o recurso da escrita é fundamental para a elaboração de um ponto de vista sobre o mundo, pois é o meio de distanciamento e de teorização que permite passar do conjuntural, gerado pelo oral, ao estruturado, expresso pelo texto. Stumpf (2000, p. 2) defende a escrita de sinais, afirmando que:

O escrever e ler em língua de sinais, para o surdo, é o caminho natural. Será que para uma pessoa ouvinte submetida a uma Educação Bilíngue (Libras/Língua Portuguesa) preconizarse-ia como acertado dar-lhe condições para ler e escrever em sua segunda língua, deixando para sua primeira língua apenas o papel da comunicação presencial e imediata? 
$\mathrm{Na}$ verdade, isso aconteceu muitas vezes na história da humanidade, quando populações foram forçadas a esquecer suas línguas naturais. Sabemos, pelas constatações da sociolinguística, o quanto essas populações foram prejudicadas por esses procedimentos coercitivos.

É preciso compreender a diferença entre língua falada e língua escrita, para não confundi-las achando que são os mesmos meios de comunicação. Correia (2014, p. 2) apresenta os meios de comunicação de forma distinta: "A escrita representa um estágio posterior de uma língua. A língua falada é mais espontânea, abrange a comunicação linguística em toda a sua totalidade. A língua escrita não é apenas a representação da língua falada, mas, sim, um sistema mais disciplinado e rígido”.

O presente artigo, portanto, objetiva descrever, morfológica e sintaticamente, os processos morfológicos e a organização sintática do texto escrito no sistema SignWriting, com suas unidades combinadas, tornando-o mais produtivo e criativo. Uma das hipóteses levantadas é de que a escrita de sinais pode apresentar-se de uma forma transparente e clara para descrever, especificamente, a flexão de plural.

Para a discussão a ser feita neste artigo, o enfoque da morfologia gerativista será apresentado de forma bem geral, acompanhado da conceituação e da descrição de alguns morfemas livres e presos, bem como das competências dos humanos, que possuem a gramática completa da língua (CHOMSKY, 1970). Esperamos que sejam abertas perspectivas inovadoras que provoquem novas reflexões.

O estudo sobre a morfologia das línguas faladas ou orais vemse desenvolvendo há muitos anos. Embora as teorias e nomenclaturas variem, temos um conhecimento bastante claro e aprofundado sobre o seu funcionamento. De forma diferente, a morfologia da língua de sinais apresenta-se, hoje, numa fase inicial e complexa, não só porque seu estudo iniciou-se recentemente, mas também porque se trata de uma língua de realização viso-espacial. 
A língua de sinais, enquanto língua que se realiza no espaço, não pode apresentar exatamente os mesmos fenômenos, mas pode ser analisada segundo os mesmos parâmetros e com a mesma terminologia das línguas orais. Assim, os morfemas identificados nos sinais existem também nos gestos e é possível detectar, neles, unidades significativas mínimas que devem ser procuradas na configuração da mão, na localização, na direção do movimento, nas expressões faciais e nos movimentos do corpo.

\section{Criatividade, produtividade e os morfemas de plural na escrita da Libras}

Criatividade e produtividade são características que as línguas naturais têm de produzir um número infinito de frases a partir de uma quantidade finita de elementos de enunciados, com um número limitado de elementos, por meio da combinação e recombinação destes. A língua põe à disposição de seus usuários um total determinado de elementos (fonemas, morfemas, estruturas sintáticas) a partir dos quais os usuários podem criar sentenças em número infinito. Por exemplo, o usuário tem duas sentenças, como: "A casa é branca" e "A casa é bonita". Empregando a capacidade de criatividade e produtividade que a língua lhe oferece, ele combina as duas e produz: "A casa branca é bonita".

Para a flexão de plural da língua portuguesa, por exemplo, a produtividade ocorre com o simples uso da desinência “-s", como se

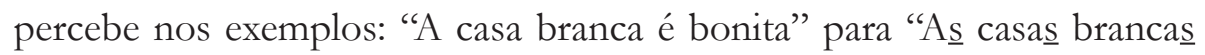
são bonitas". Na morfologia flexional de plural das línguas de sinais, há uma maior produtividade, por apresentarem maior variedade de repetição.

No material sobre morfologia organizado por Silva (2009) para o curso de Letras Libras, há uma busca por algumas propostas de Câmara Jr. (1970), que descreve como a morfologia trabalha. A pesquisadora explica que a palavra é um conjunto de um ou mais morfemas, com som e sentido, que se comporta como forma livre ou como forma dependente 
na língua. Brasileiros podem reconhecer os "pedaços de palavras" mesmo em palavras nunca ouvidas anteriormente, com significado, como, por exemplo, o termo anticonstitucionalissimamente, se souberem, tão somente, o significado de constituição. "Constituição" significa: um instrumento de bierarquia máxima, que visa regular as normas organizacionais e mantenedoras do Estado, sendo um conjunto de normas jurídicas. Do significado dos elementos derivam novas palavras em português: - al, "elemento que transforma um substantivo em adjetivo"; -íssima, "elemento que traz um adjetivo para o grau superlativo com uma característica de maior intensidade"; -mente, "elemento que transforma um adjetivo em advérbio"; -anti, "elemento que não produz mudança de classe gramatical, mas modifica o significado para negativo". Assim, ao adicionarmos constituição e -al, criamos o adjetivo constitucional e, ao formarmos constitucionalíssima, temos o grau superlativo do adjetivo. Finalmente, ao somarmos -mente com constitucionalíssima, formamos o advérbio, e anti- será o negativo. Os elementos que carregam significado das partes constituintes das palavras são rotulados de morfemas. Os brasileiros também sabem as regras que pertencem à língua, como, por exemplo, em anticonstitucionalissimamente, onde existem quatro elementos de morfemas presos, como anti-, que aparece em anti-higiênico ou em antiaéreo, -al, que aparece em nacional ou social, -íssima, que aparece em lindíssima ou belissima, e -mente, que é reconhecido por felizmente ou certamente.

A corrente de pensamento estruturalista também pondera acerca de algumas preocupações da linguística, considerando que:

[...] uma das preocupações da Linguística é tentar explicar como reconhecemos palavras que nunca ouvimos antes e como podemos criar palavras que nunca foram proferidas antes. A resposta é que nosso conhecimento dos morfemas da língua é o que nos dá esta capacidade. (MUSSALIN; BENTES, 2012, p. 2).

Os falantes nativos da língua portuguesa, como português vernáculo, compreendem e reproduzem a regra, já vislumbrando muitas 
outras palavras com anti-. Podemos afirmar que, em todas essas palavras, tal forma presa vai aparecer sempre no começo da palavra, como prefixo, e nunca ao final dela, assim como -al, -íssima e -mente sempre ocorrerão no final da palavra, e nunca no começo, já que são sufixos.

A flexão não é um processo morfológico para criar palavras novas; aplica-se às palavras variáveis, permitindo especificar suas propriedades morfossintáticas, ou seja, serve para construir formas diferentes de uma mesma palavra. Existem, contudo, alguns morfemas que adquirem um caráter de obrigatoriedade e de regularidade no processo que não se vê na derivação.

Um exemplo de uma forma morfologicamente marcada no português é a desinência de número plural, manifestada pela desinência /-s/ em posição pós-vocálica final. No entanto, uma distinção entre o Português e a Libras, no que diz respeito à formação do plural, é que na Libras, acontece em duas classes gramaticais, na substantiva e na verbal, diferentemente do Português, que não apresenta marcação desinencial para verbos, tal como o faz para o plural dos substantivos (com /-s/). Na Libras, a marcação de plural nos substantivos e verbos é produzida geralmente no espaço neutro, sem tocar a parte do corpo (peito, ombro e cabeça), usando o mesmo glifo, ou seja a mesma desinência, de marcação do plural.

Battison (1978), ao analisar aspectos linguísticos da língua de sinais americana, define que:

[...] podemos medir o número de execuções unitárias ou batidas que são necessárias para articular um sinal. [...] Assim, uma única execução ou batida é um ciclo completo de um sinal, sem que nenhuma parte dele seja repetida. [...] Alguns plurais substantivos são formados desta forma, por exemplo, e algumas flexões verbais são marcadas por diferentes tipos de repetição. (BATTISON, 1978, p. 53) [tradução nossa]. 
Para a formação plural dos verbos e dos substantivos na Libras, temos um morfema preso, que é a repetição do espaço da forma morfologicamente marcada com uma desinência de glifo (II) e também (I). Para entender melhor como se dá esse processo, criamos uma nova proposta para uso da marcação do plural na escrita em SignWriting.

A formação do plural na escrita de sinais discutida nesta pesquisa ocorre, muitas vezes, por um dos parâmetros que é o ponto de articulação feito no espaço neutro, que pode ser bem aproveitado com a nova proposta de dois tipos glifos (vertical ou horizontal). Quanto ao verbo com concordância regular número-pessoal em que as direções de movimentos marcadas no pronome pessoal do plural em escrita de sinais, este já possui algumas regras claras do tipo espacial de repetição no sentido horizontal que indicam duas ou três pessoas usando a direção de movimentos que se repetem para objeto. A formação de plural em escrita de sinais que possui a direção de movimento para indicar o pronome pessoal, portanto, de modo geral, em que a desinência de glifo (II) ou (I) não poderá substituir a flexão verbal, numa categoria de concordância regular número-pessoal.

Antes de nossa proposta, escrevia-se o plural naturalmente com a repetição e a cópia dos movimentos que um sinal já possui. Quando se

¿uve o sinal TRABALHO, tem-se que o movimento do sinal é este: لر ; assim, copia-se duas vezes o mesmo glifo. Quando se escreve o sinal FUNDAR, tem-se um tipo de contato representado por escovar (mão se arrasta) entre duas linhas verticais $|\mathfrak{O}|$ em um sinal, repete-se duas vezes para a formação de plural ' $\mathbf{O}_{\text {vezes, }}$ copia-se duas vezes a repetição com um contato e movimento $|\oplus| \boldsymbol{\Pi}$. Alguns leitores reclamaram da falta de indicação para saberem se o plano era o horizontal ou o vertical, até que surgiu uma tentativa para acrescentar o movimento representado por uma seta dupla $\overparen{ح}$ (vertical ou paralelo à parede) e uma seta simples (horizontal ou paralelo ao chão), que, no entanto, não é compatível com a escrita na formação de plural. Como não havia uma convenção, a partir da observação percebeu-se a necessidade de criar uma proposta nova com 
diretrizes claras e compatíveis tanto com o sistema SignWriting quanto com as regras gramaticais.

Enfim, antes da nova proposta com a desinência de glifo para marcação do plural em relação aos planos horizontal e vertical, tínhamos outro tipo de plural, representado assim:

\section{Quadro 1. Representação do plural}

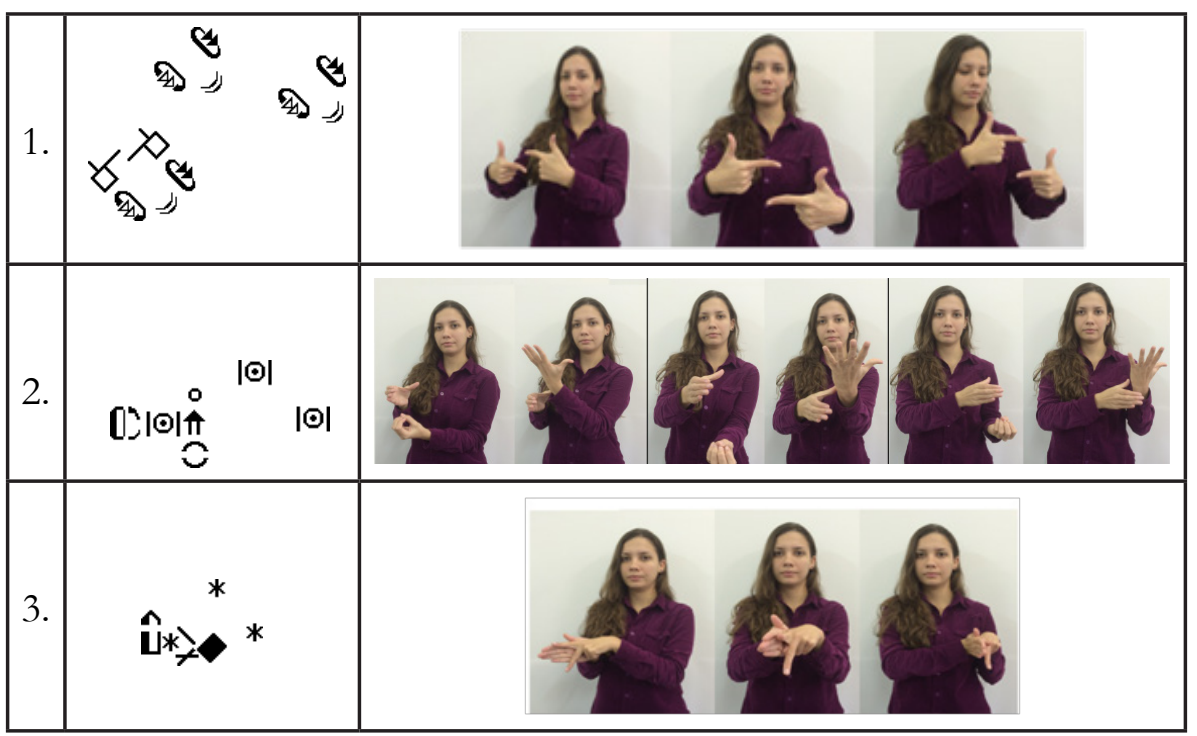

Fonte: Elaborada pela autora.

Para compreender as ilustrações:

1. Trabalbar (com plural);

2. Fundar (com plural);

3. Próprio (com plural).

Ponderamos que o que atrapalha, no mc e do registro escrito,

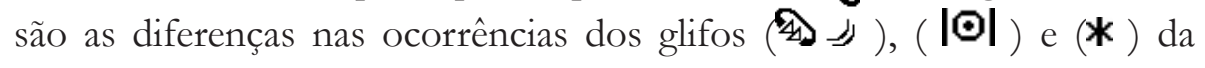
repetição, que não estão sendo padronizados e que também permitem 
uma confusão na definição dos espaços nos planos horizontal ou vertical. As imagens são apenas ilustrativas, visando à compreensão da produção do sinal no formato horizontal, diferentemente da escrita de sinais, que pressupõe uma ambiguidade. Ao se produzir os sinais na Libras falada, usamos os dois planos: vertical e horizontal.

Durante uma reunião do grupo de estudos formado por pesquisadores e alunos interessados em discutir a escrita de sinais, que ocorre uma vez por semana na Universidade Federal de Santa Catarina, um participante, aluno do curso de Letras Libras, sugeriu uma nova proposta de glifos para desinênria de plural, adotando os movimentos que já possuem regras, por exemp

Em sentido vertical, $\Downarrow \Downarrow \mathbf{y}$ é um paralelo à parede (vertical), cujo movimento vai para cima ou para baixo, com escritos das setas de dupla haste. O primeiro sinal, BRASIL, que vai para baixo, e o segundo sinal, IDADE, que vai para cima, devem ser colocados com ${ }^{2}$ s setas de dupla haste. No caso do ( $($ al BRASIL, pela seta para baixo $(\Downarrow)$, tem aue misturar com as curvas (\$); já o sinal IDADE, pela seta para cima ( $\mathbf{\pi}$ ), como aponta o exemplo abaixo:

\section{Quadro 2 - Sinais escritos com as setas de dupla haste são} traduzidos para a língua portuguesa e com imagens da Libras

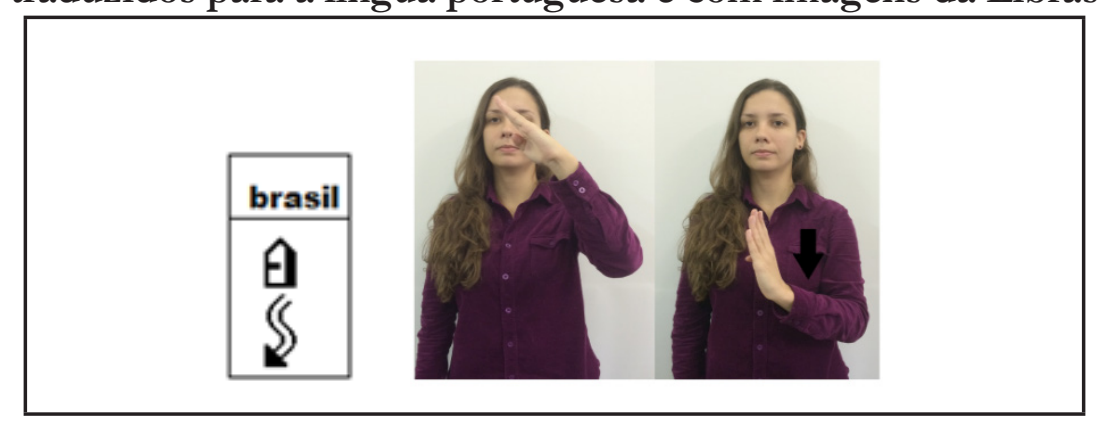




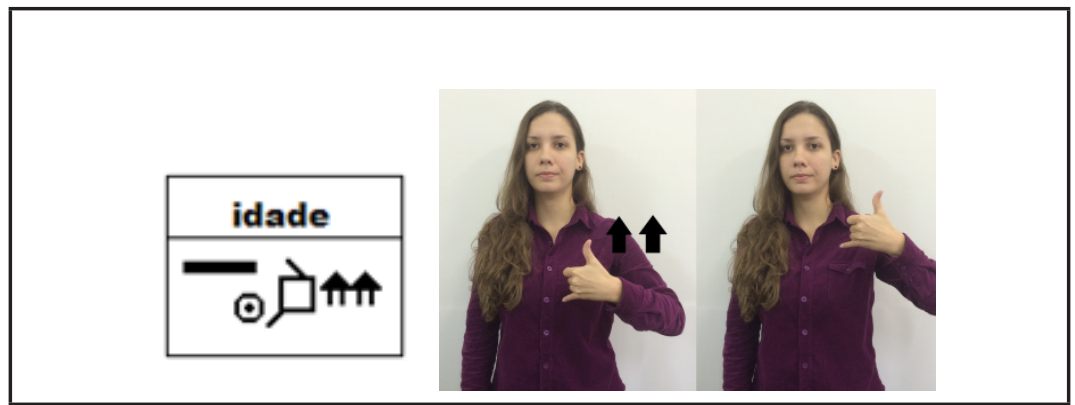

Fonte: Elaborada pela autora.

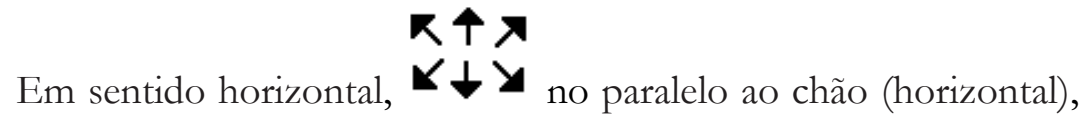
que vai para a frente ou para trás, os escritos das setas são de haste simples. O primeiro sinal, BFBER, que vai para trás, deve ser colocado com a se ${ }^{+\wedge}$ de haste simples $(\downarrow$ ); já o sinal COMEÇAR, pela seta para a frente ( $\uparrow$ ), conforme mostra o exemplo:

Quadro 3 - Sinais escritos das setas de hastes simples são traduzidos para a língua portuguesa e com imagens da Libras
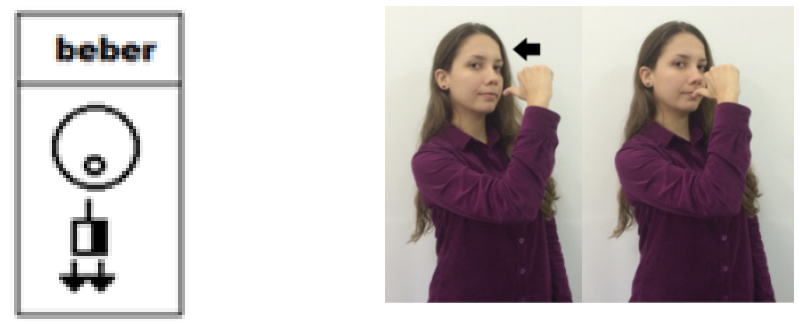


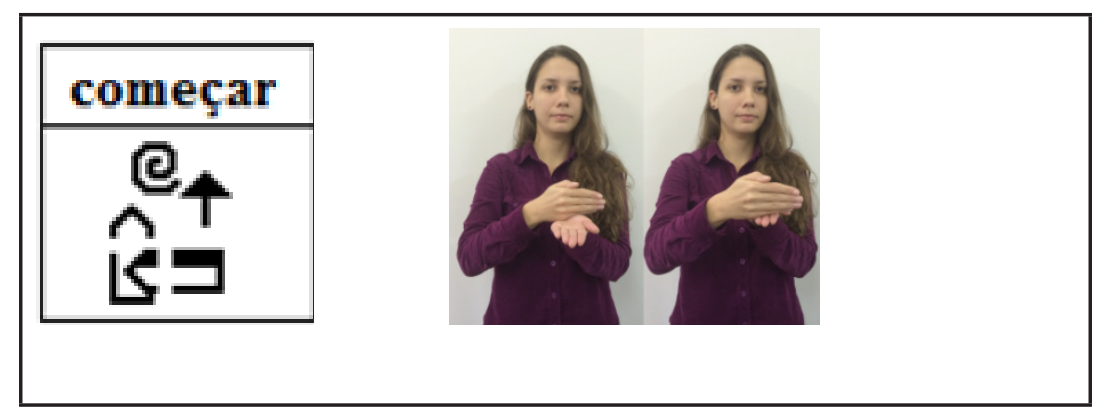

Fonte: Elaborada pela autora.

Ao adotar os movimentos existentes - vertical e horizontal - nos exemplos citados acima, estes se transformam também na ocorrência de plural, excluindo a seta para os glifos (II), no plural, de sentido vertical e (I), em plural de sentido horizontal. Não há, portanto, por parte dos nativos falantes da Língua Brasileira de Sinais, um acréscimo ou uma criação de novos glifos para o espaço em horizontal e vertical, como (II) e (I). Esses glifos já existiam no software desenvolvido para o sistema de escrita no site SignPuddle ${ }^{3}$, criado por Valerie Sutton (2003), servindo para nós, sinalizadores, que criamos ou traduzimos os sinais na escrita.

Ao criarmos os sinais para a escrita no software do site SignPuddle, não utilizamos, inicialmente, os glifos (II) e (I), por não sabermos para que eles serviam, mas compreendemos agora a propriedade de seu uso para os morfemas presos, em virtude dos movimentos que não podem ficar isolados.

$\overline{3}$ Disponível em $<$ http://www.signbank.org/signpuddle/>. 
Quadro 4 - Sinais escritos com nova proposta para marcação de plural

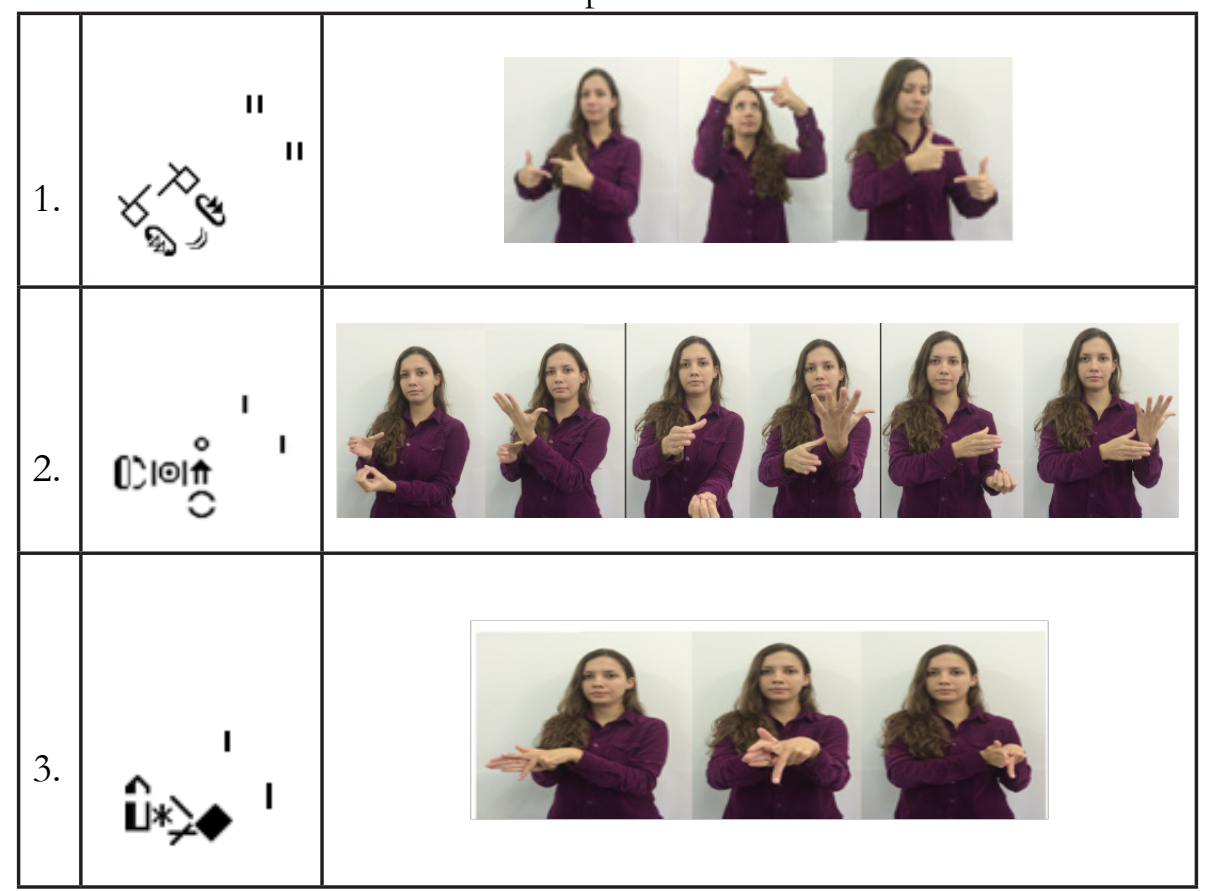

Fonte: Elaborada pela autora.

Legendando novamente as ilustrações:

1. Trabalhar (com plural em vertical);

2. Fundar (com plural em horizontal);

3. Próprio (com plural em horizontal).

Percebemos que já existe maior proximidade de marcação, observando-se ser mais comum somente entre dois glifos, padronizados e com regularidades de número plural - que também é manifestado no final. Primeiro, escreve-se ou lê-se o sinal, para, posteriormente, registrá-lo em 
horizontal ou vertical, dependendo do contexto da frase. Por outro lado, os glifos não podem estar isolados, pois não são sinais formados; logo, sua leitura e compreensão sempre irão depender da comparação entre um ou mais parâmetros, para que um sinal que tenha determinada configuração de mão seja composto com um morfema preso, tal como a desinência /s / na língua portuguesa.

\section{Análise da marcação do plural nas produções escritas dos alunos aprendizes de Signwriting}

É importante destacar os fatos relativos à coleta dos dados: nos dois primeiros dias de aula, com dez alunos presentes, o primeiro passo foi conceituar a morfologia, para a compreensão da relação entre leitura e escrita de sinais, com as descobertas de morfemas e a produção com morfemas nas frases, podendo, com isso, estabelecer-se a análise. Também foi necessário verificar a aceitação e as críticas, por parte dos alunos, quanto à nova proposta de plural apresentada.

Com mais facilidade e rapidez para escrever a marcação de plural, a proposta é que sempre se coloque um glifo com apenas uma linha para o plano horizontal - ou duas linhas - para o plano vertical -, só escrevendo os morfemas em um glifo caso eles se repitam duas vezes, com ( II ) ou (I ) após determinado sinal. Observe a representação no esquema a seguir: 
Quadro 5 - Representação de espaços em duas formas: triângulo ou uma direção

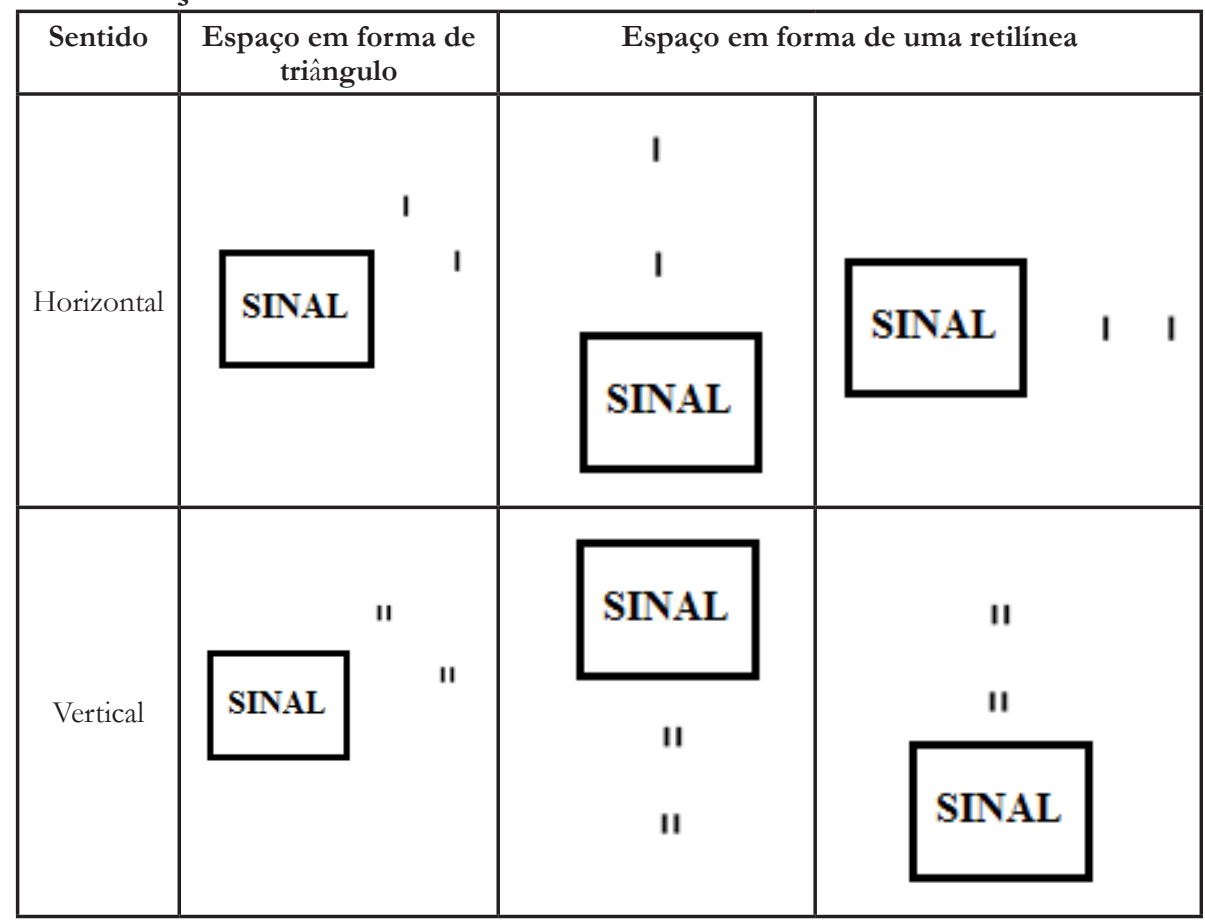

Fonte: Elaborada pela autora.

No sentido horizontal são apresentados três exemplos de sinais com a marcação de plural no espaço, em forma de triângulo ou seguindo uma linha reta. Onde cada repetição para marcação de plural representa um significado diferente. $\mathrm{O}$ exemplo de direita para esquerda no sentido horizontal mostra primeiro sinal e, em seguida, sua repetição para frente e, posteriormente, para trás, formando assim um triângulo; o segundo sinal apresenta uma repetição do sinal para frente e se repete mais uma vez para frente, constituindo-se um espaço de uma linha reta; bem como o terceiro sinal dirige-se para o lado direito e se repete mais uma vez para esse mesmo lado. Já no sentido vertical observa-se movimento da 
direta para a esquerda, em que o primeiro sinal se repete para cima e para baixo em forma de triângulo; o segundo sinal é repetido numa retilínea se direciona para baixo e novamente para baixo, assim como o terceiro sinal se apresenta seguindo uma retilínea para cima e repetindo-se para cima.

A escrita da língua de sinais é bem flexível e contempla trocas na marcação do plural no espaço, como também a inversão na ordem, desde que os glifos de marcação do plural continuem grafados ao final. Veja outro exemplo:

\section{Quadro 6 - Representação de inversão na ordem}

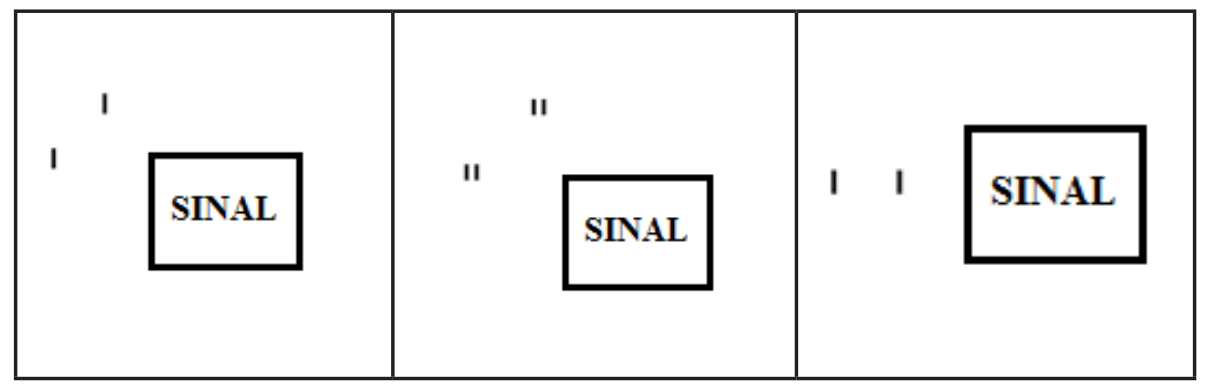

Fonte: Elaborada pela autora.

A inversão na ordem de espaços nas duas formas, de triângulo ou em uma retilínea pode ser elaborada no sentido horizontal e no sentido vertical como observa-se no quadro 6.

A proposta nova de plural por (II) e (I) na escrita de sinais apresentada em aula foi aceita rapidamente pelos alunos. Assim, formaram-se duplas para escrever uma frase que tivesse plural na repetição da sinalização, na escrita de sinais, divididas por temas diferentes, como descrito a seguir: 
Quadro 7 - Atividade em escrita de sinais para alunos escreverem uma frase

\begin{tabular}{|c|c|c|c|}
\hline Letras-Libras & $8^{\circ}$ ENELL & Congresso de Milão & Educação à Distância \\
\hline$-\frac{\psi}{W}$ & 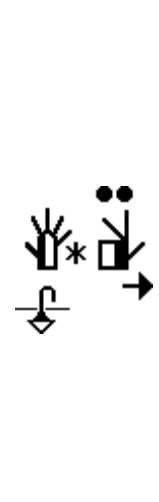 & 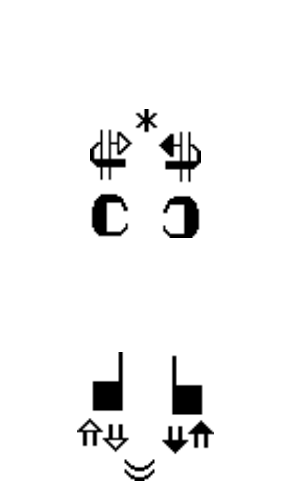 & ל⿺ \\
\hline
\end{tabular}

Fonte: Elaborada pela autora.

Os quatro temas foram escolhidos por estarem relacionados com o curso de Letras-Libras, possivelmente, pela maior quantidade de participantes envolvidas. O primeiro tema abordado versa sobre o curso de Letras Libras de modo geral, um curso universitário, que cujo objetivo de formar estudantes para se tornarem profissionais docentes ou intérpretes e tradutores de Libras/Português. O segundo tema trata-se do $8^{\circ}$ ENELL, sendo este o oitavo Encontro Nacional de Estudantes de Letras-Libras, realizado em 2014, para discutir temáticas relacionadas à comunidade surda brasileira, sua língua - a Libras - e sua cultura. O terceiro tema é sobre o Congresso de Milão, ocorrido em 1880, na Itália. Este teve como participantes, convidados de vários países para discutir, apresentar e votar sobre a educação de surdos. Quanto ao quarto tema, este também se relacionava ao curso de Letras-Libras, mas agora focalizando nas suas edições à distância, em 2006 e 2008. Esse foi o primeiro curso de LetrasLibras desenvolvido na modalidade à distância, em rede nacional, com nove polos na primeira edição (2006) e quinze polos na segunda (2008). 


\section{Dupla $n^{\circ} 1$ :}

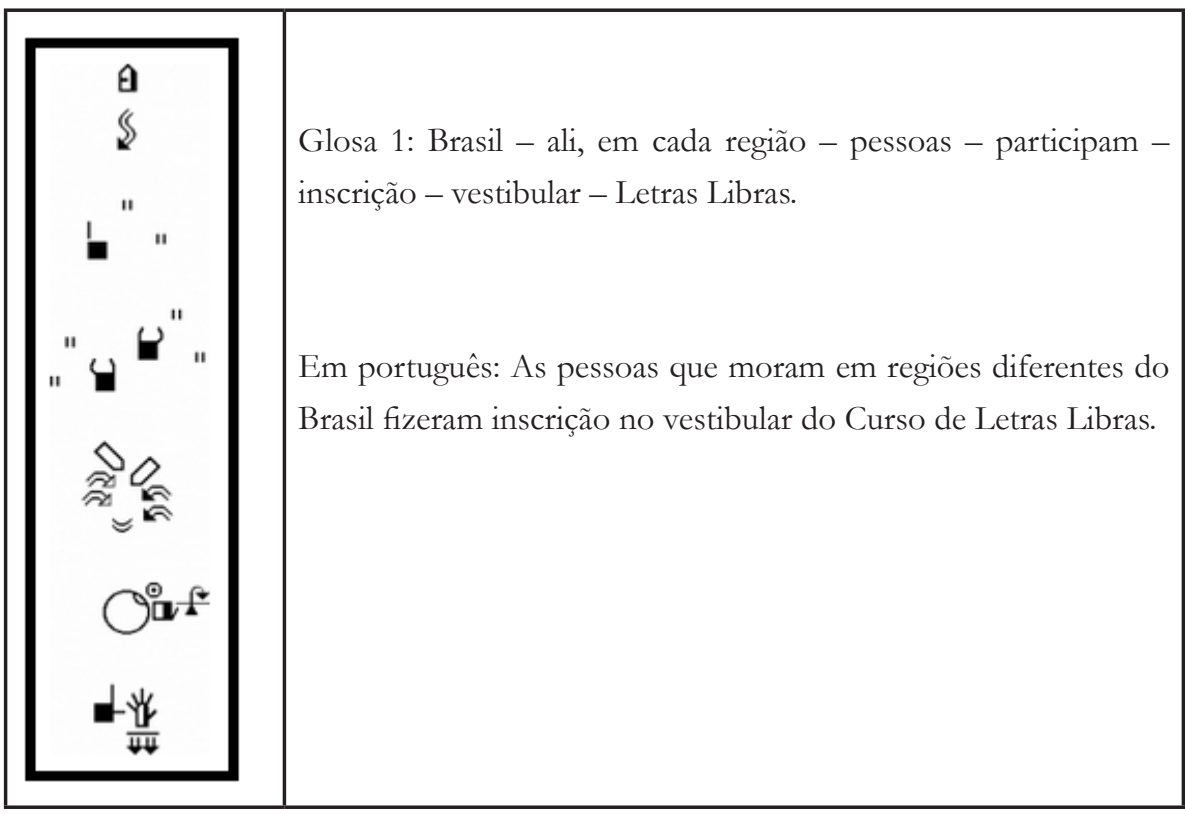

A primeira dupla de alunos, composta por dois surdos, colocou dois sinais em plural (II). Surpreendeu terem colocado o plural "pessoas", usando o “㨁 ' das setas de dupla haste, mesmo que existisse o padrão pelo $\Downarrow \Downarrow \Downarrow \Downarrow \Downarrow$. Os alunos naturalmente aceitaram fazer a substituição também pela frase mais clara, com melhor combinação. No contexto, já está a relação com a sintaxe, mostrando onde as pessoas moram, não somente em um lugar ou Estado, mas em alguns Estados do Brasil, e que fizeram inscrição no vestibular. É a maneira de tornar mais clara a escrita por causa de um glifo referente à seta vertical junto com a maior quantidade dos participantes. No início da frase, a inserção do sinal "Brasil" influencia a referência de "ALI EM CADA REGIÃO" e "PESSOAS", pois sugere vários locais em um mesmo território e o uso do sinal escrito de "INSCRIÇÃO", com a utilização de dois glifos, representados por $(\bullet)$, que descrevem 
o movimento de abrir e fechar as mãos mais de uma vez. Isso permite traduzir que várias pessoas inscreveram-se no curso de Letras Libras, visto pelo sinal de cada região no contexto. Caso qui " " $\mathrm{m}$, a inscrição feita por vários Estados poderia ser representada por $\dot{\cup}$, e se optassem por representar apenas uma pessoa inscrita, isso poderia ser feito com um só glifo de movimento, como o seguinte: $\hat{\mathrm{U}}$

\section{Dupla $n^{\circ} 2$ :}

\begin{tabular}{|l|l|l|} 
Glosa 2: $8^{\circ}$ Enell - encontro - Brasil - todas - \\
pessoas - contato - vários - alunos - Estados - \\
vir - também - professores - convidar - enviar \\
e-mail - criar - responder - bom - palestra - \\
vários. \\
Português: $8^{\circ}$ Enell foi um encontro nacional. \\
As pessoas da comissão de organização \\
entraram em contato com vários alunos de cada \\
Estado, como também convidaram professores, \\
pelo e-mail enviado criado por evento, que \\
vieram e participaram da realização de diversas \\
palestras, obtendo resultados satisfatórios.
\end{tabular}

A segunda dupla de alunos, um ouvinte e um surdo, soube diferenciar os espaços de horizontal (I) e vertical (II). E, sem combinar com os outros

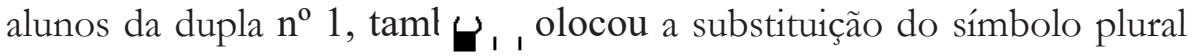
do sinal "PESSOAS" por $\Downarrow$, diferentemente da primeira dupla, que escolheu uma representação vertical no espaço mais acima, em referência ao sinal de Brasil. Isso reitera a afirmação de que a escrita dos símbolos depende do contexto de uso. Nele, pela forma horizontal, entende-se que 
as pessoas que moram em Florianópolis entraram em contato com alunos de vários Estados. E depois, na frase "VÁRIOS ALUNOS ESTADOS", mudaram para o glifo vertical, por ser a referência no Brasil, e a partir de "OS CONVIDADOS PROFESSORES, POR E-MAIL" seguem a mesma, em vertical.

É interessante perceber que verbos como CONVIDAR, ENVIAR E-MAIL e VIR possuem concordância número-pessoal, assim como o verbo CONVIDAR é um verbo de concordância reserva ${ }^{4}$, sendo a direção de movimento oposta à de concordância regular. Já o verbo ENVIAR E-MAIL é um verbo de concordância regular, mas não apresenta sentido horizontal. No entanto, ao interpretar o texto produzido pelos alunos da segunda dupla tal verbo foi usado de forma genérica, não especificando quais professores seriam convidados. Isso talvez tenha se dado devido aos verbos usados no contexto, CRIAR e CONVIDAR, mantendo assim a concordância da frase. Quanto ao verbo VIR não foi colocado a marcação de plural. Nisto percebe-se a oportunidade para um estudo mais aprofundado sobre a distinção entre os dois sentidos na marcação de plural e também a direção de movimento no pronome pessoal do plural.

Assim, a sintaxe pode ser demonstrada, claramente, com a observação dos princípios da gramática. Por sua vez, a primeira dupla deu a entender que eram as pessoas em cada Estado, por causa do glifo vertical.

${ }^{4}$ Há verbos como CONVIDAR, duplo reverso, em que, ao contrário de AVISAR, duplo normal, o início do movimento marca o objeto (quem é convidado) e o fim, o sujeito (quem convida)" (XAVIER \& NEVER, 2016, p.136) 


\section{Dupla $n^{\circ} 3$ :}

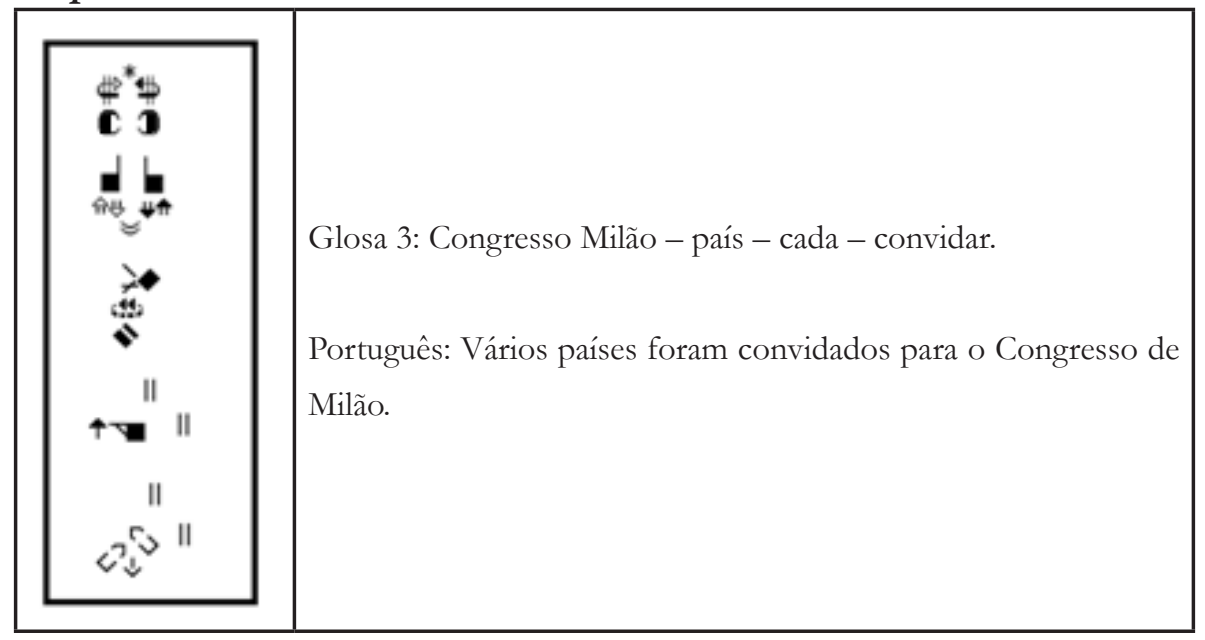

Já a terceira dupla, composta por um ouvinte e um surdo, apresentou um fato que surpreendeu: o sinal "PAj ¿ " te não foi colocado no plural e que poderia ser representado por $($ "). Ao contrário, os alunos preferiram acrescentar o sinal "CADA" em ( $\ "$ "), na forma horizontal, que serve como um auxiliar, como uma informação de que seriam vários países do mundo. Se não fosse colocado o sinal "CADA", os leitores que não conhecem a história do Congresso de Milão iriam pensar que: "um país, que é a Itália, convida pessoas que moram em um único país". Por isso, acrescentou-se mais um sinal "CADA"; sendo esta informação importante para esclarecer que os convites foram enviados a diferentes países. Usando o verbo CONVIDAR representado, assim como relatado pela segunda dupla de alunos ao tratar-se do tema sobre o $8^{\circ}$ ENELL, com o uso de glifo (II ). Dessa forma, a dupla refere-se a cada estado do Brasil, semelhante aos colegas que, em seu texto, trataram de pessoas que moravam em diferentes países no tema sobre o Congresso de Milão. $\mathrm{O}$ conhecimento da escrita necessita de mais uma informação e não pode ser igual à língua falada, de uma forma restrita, uma vez que faz parte a organização da sintaxe. 


\section{Dupla $\mathrm{n}^{\circ} 4$}

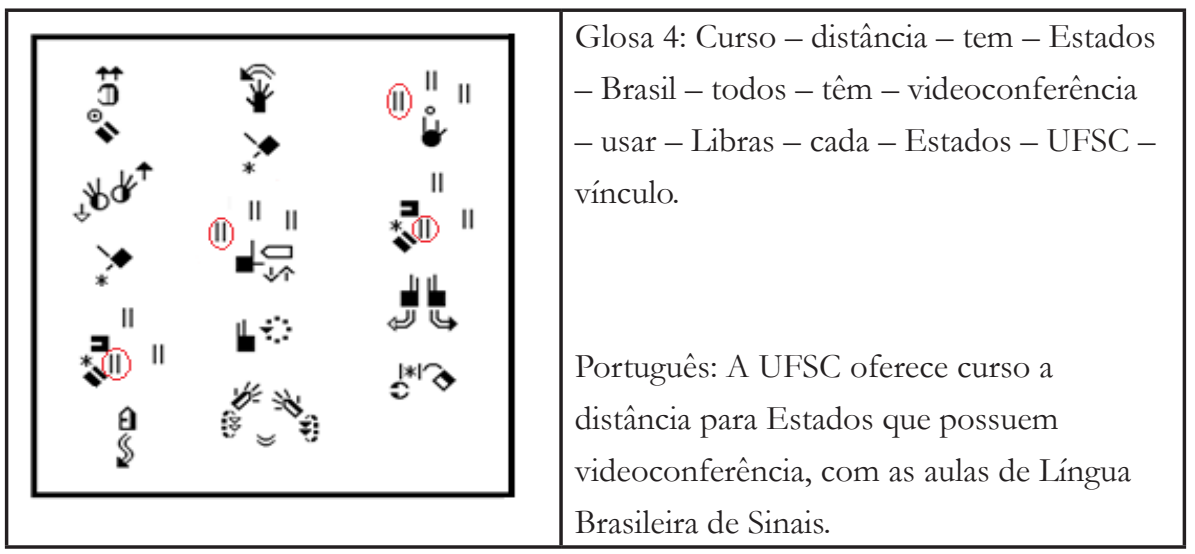

Percebe-se que a quarta dupla, composta por dois surdos, diferenciase por ter colocado três glifos em vertical, o que não seria necessário, pois já temos representado, de forma clara, o sinal com a configuração da mão e o movimento de "ESTADOS", assim como a configuração e o movimento dos sinais "VIDEOCONFERÊNCIA" e "CADA". Ao se colocar três glifos na vertical, a representação torna-se confusa, por não permitir identificar claramente onde a mesma se inicia, já que a configuração da mão está no meio dos três glifos de plural. Seria mais adequado continuar com o padrão, como foi apresentado pelos alunos dos grupos $n^{\circ} 1, n^{\circ} 2$ e $\mathrm{n}^{\circ} 3$, que somente colocaram dois glifos na escrita, ao final.

\section{Considerações Finais}

Este artigo não é um trabalho definitivo, apenas um ponto de partida para a descrição de um aspecto da morfologia e da sintaxe na escrita da Libras. Há alguns pontos que ainda não são claros, em relação aos quais continuaremos a ter muitas dúvidas e, uma vez que sobre os quais se sabe tão pouco, continuaremos a pesquisar. Os alunos do curso 
de Letras Libras que produziram a escrita de sinais para coleta dos dados reconheceram a importância da escrita de sinais, mas alguns continuam a questionar e resistir ao seu uso. Sabemos que muitos fatores da história pessoal e coletiva dos surdos explicam essa conduta, porém não se trata de buscar a unanimidade. Acreditamos que os alunos compreenderam que, além de aprender a Libras escrita em contexto de sala de aula, há também alternativas em Libras para os sinais escritos.

Os estudantes sentiram-se motivados com a descoberta da relação entre morfologia e sintaxe ao entrar em contato com o exercício de marcação de plural proposto, aumentando a curiosidade em receber mais atividades e mais práticas ao escrever os sinais, uma vez aprendidas as regras básicas que tratam sobre a flexão das palavras. A maioria deles já aceita e faz uso, com facilidade, dos glifos novos (I) e (II) aprendidos na sala de aula, demonstrando satisfação por escrever rápido e saber que existe uma forma padrão na escrita do plural, definido como um morfema preso, enriquecendo, assim, seu conhecimento gramatical e sua produção.

Por fim, esperamos que a marcação do plural na escrita de sinais torne-se válida e clara para os estudos morfossintáticos, com um maior detalhamento teórico e melhorias gramaticais da frase. Esperamos também que sejam difundidos ainda mais os sinais com formação de plural em diversos suportes, tais como livros, revistas e redes sociais, o que possibilitará mais análises que identifiquem, quantitativamente, os sinais marcados como plural em SignWriting.

\section{Referências}

BATTISON, R. Lexical Borrowing in American Sign Language. Silver Spring, Md: Linstok Press, 1978.

CAMARA JR.,. J. M. O Estruturalismo. Alfa: Revista de Linguística, São Paulo, v. 11, 1967. 
CAMPOS, D. W.; STUMPF, M. R. Cultura Surda: um patrimônio em contínua evolução. Curitiba: Editora CRV, 2012.

CORREIA, A. Comunicação oral e escrita aplicada. Instituto Formação: Cursos Técnicos profissionalizantes, 2014.

CHOMSKY, N.; HALLE, M. The sound pattern of English. Nova York: Harper and Row, 1968.

FIGUEIREDO, M. Morfologia. Florianópolis: Curso de Letras Libras a Distância, 2009.

GARVIN, P. A Prague School Reader on Esthetics, Literary Structure and Style, selected and translated from the original Czech. Washington D.C, 1964, p. VIII.

LIDDELL, S.K.; JOHNSON, R. E. American Sign Language compound formation processes, lexicalization and phonological remnants. Natural Language and Linguistic Theory, New York, v. 4, p. 445-513, 1986.

MUSSALIM, F.; BENTES, A. (Orgs.). Introducão à linguistica: domínios e fronteiras. 5. ed. São Paulo: Cortez, 2006.

NASCIMENTO, S. P. F. Um olhar sobre a morfologia dos gestos. PRO_LGP: Licenciatura em Língua Gestual Portuguesa. Lisboa: Universidade Católica Portuguesa Editora, 2011.

POIZER, H.; KLIMA, E.S.; BELLUGI, U. What the hands reveal about the brain. Massachusetts: Ed. Massachusetts Institute of Technology, 1987.

QUADROS, R.; KARNOPP, L. Lingua de sinais brasileira: estudos linguísticos. Porto Alegre: Artmed, 2004. 
e QUER, J. Revertendo os verbos reversos e seguindo em frente:

sobre concordância, auxiliares e classes verbais em linguas de sinais. p. 65 a 81. Org. [por] Quadros, R. e VASCONCELLOS, M. L. 90 Theoretical ISSUES in sign language research conference. Arara Azul: Florianópolis, Dezembro 2006.

SILVA, M. C. F. Morfologia. Florianópolis: UFSC, 2009.

SCHWINDT, L. (Org.). Manual de linguística: fonologia, morfologia e sintaxe. 1. ed. Rio de Janeiro: Vozes, 2014.

STUMPF, M. R. Lingua de sinais: escrita dos surdos na internet. V Congresso Iberoamericano de Informática Educativa, Vinã del Mar, Chile, 2000.

XAVIER, A. ; NEVES, S. Descrição de aspectos morfológicos da LIBRAS. Revista Sinalizar, v1, n.2, p. 130-151, jul./dez. 2016

WANDERLEY, D. C. A leitura e escrita de sinais de forma processual e lúdica. Curitiba: Editora Prismas, 2015. 